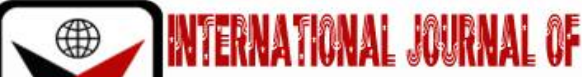

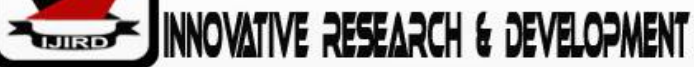

ISSN 2278 - 0211 (Online)

\section{Municipal Solid Waste Management in the Western Province of Sri Lanka: Awareness, Legal Framework or Fund Allocation?}

\begin{tabular}{c} 
Ananda Ranawake \\
Department of Graduate Studies, University of Sri Jayewardenepura, Sri Lanka \\
M.A. Shanta Wijesinghe \\
Head, Department of Geology, University of Sri Jayewardenepura, Sri Lanka \\
Nilanthi G.J.G Bandara \\
Professor, Department of Botany, University of Sri Jayewardenepura, Sri Lanka \\
\hline
\end{tabular}

\begin{abstract}
:
The intertwined relationship of extraction of waste to its disposal could be defined as Solid Waste Management (SWM). Even a quarter of a century after the UN Earth Summit in Rio de Janeiro, which recommended the 3R principle to maximize the extraction-disposal relationship, SWM have not achieved a sufficient degree of satisfaction at the global level. This article examines the effectiveness of SWM practices in the Western Province (WP) of Sri Lanka and evaluates other related issues. Primary investigations showed that 99.82 per cent of the waste collected by the local authorities (LAs) in WP end up at open dump sites. Correlation analysis carried out on 187 questionnaires showed that all independent variables have positive Spearman's rho correlations with the effectiveness of SWM. The ratio of fund allocation for SWM over other expenditures by the LAs had a great impact ( $r=0.525)$. The strength of legal framework to enforce correct SWM was of secondary importance ( $r=0.365)$. The research shows that the long-believed factorthe awareness of stakeholders-has little impact on the effectiveness of SWM. Under these conditions, on the basis of the results of the present investigations, the article recommends enhancing fund allocation to build infrastructure for SWM and strengthening the law enforcement scenario to achieve an effective SWM. The results can be generalized for other provinces of Sri Lanka and other developing countries as well where Corruption Perception Index is high.
\end{abstract}

Keywords: Extraction-disposal relationship, $3 R$ principles, environmental awareness, developing countries, effectiveness of SWM, corruption

\section{Introduction}

Five basic phases of the consumer cycle are extraction, production, distribution, consumption and disposal. The art of harmonizing the relationship between resource extraction and its disposal after utilization could be defined as Solid Waste Management (SWM). Mass consumerism always used to be a phenomenon common to all civilities. This phenomenon rapidly expanded during late 18th century parallel to the industrial revolution. At present, consumerism has been further developing without limits. Ancient civilities stopped traveling to change their contaminated territories being eradicated from the earth when indirect extraction through agriculture became marginally unproductive (Tainter 2009). Another reason for such eradications was the territorial contamination caused by human disposals, because they were not able to control territorial contaminations in their newly built permanent civilities. In the present world, marginal productivity is evident by economic crisis, while territorial contamination is evident by damages caused by wrong SWM. If no positive responses are found with regard to these two factors, such days when our actual civility will be eradicated could be measured in decades.

Responding to this situation, United Nations Conference on Environment and Development (UNCED) has declared that the general consumption of commodities by human beings that has reached to a non-returning point should keep under control (UNCED 1992). For the purpose they recommend that the state of current knowledge on SWM represented by the 3R Principles, namely, Reduce, Reuse and Recycle. Adopting 3R principles, raw materials could be re-extracted from disposed waste, which is the last phase in mass consumerism.

Adopting the 3R principles in SWM could mitigate the extracting of raw material from the earth, which is the first phase of consumerism. The adoption of $3 \mathrm{R}$ is also a response to environmental pollution, over-production and overconsumption (Gordon 2015). Because mass consumerism is not a reversible phenomenon, there are no alternatives other than adopting the $3 \mathrm{R}$ principles.

About a quarter of a century has elapsed since the UNCED resolution of 1992 has been passed (UNFCCC 2006). Yet, the success of SWM efforts seems to be a global failure. Therefore, a necessity for evaluation of SWM practices has emerged in the global scale. 
European Union (EU) is the political region where themost successful SWM initiatives are being implemented. According to the guidelines of the EU for correct SWM, there must be at least 85 per cent of waste collection ratio. The ratio of recovery of raw material should be 90 per cent (EC 2016). By fixing 70 per cent recovery and just 10 per cent landfill target for all members, the EU is planning to achieve zero SWM by 2030. Figure 1 illustrates the 'Zero Waste Hierarchy,'a process adopted for effective SWM practices (Scottish Government 2014).

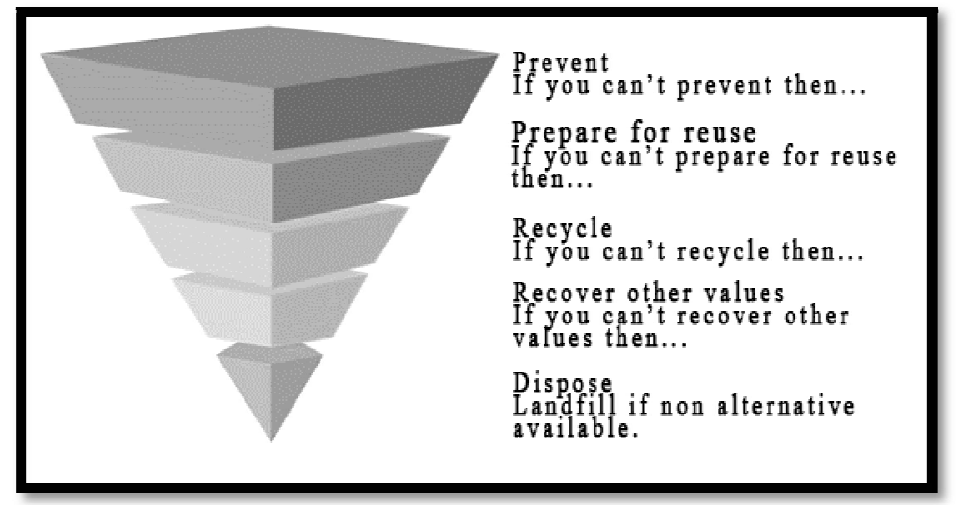

Figure 1: The Zero Waste Hierarchy

Source: Scotland's Environment Web, The Scottish Government

Sri Lanka is a developing country having an evident SWM crisis. As shown in Figure 2, the common disposal methods adopted in the Western Province (WP) of Sri Lanka are open burning and dumping (Western Province Provincial Council 2016).

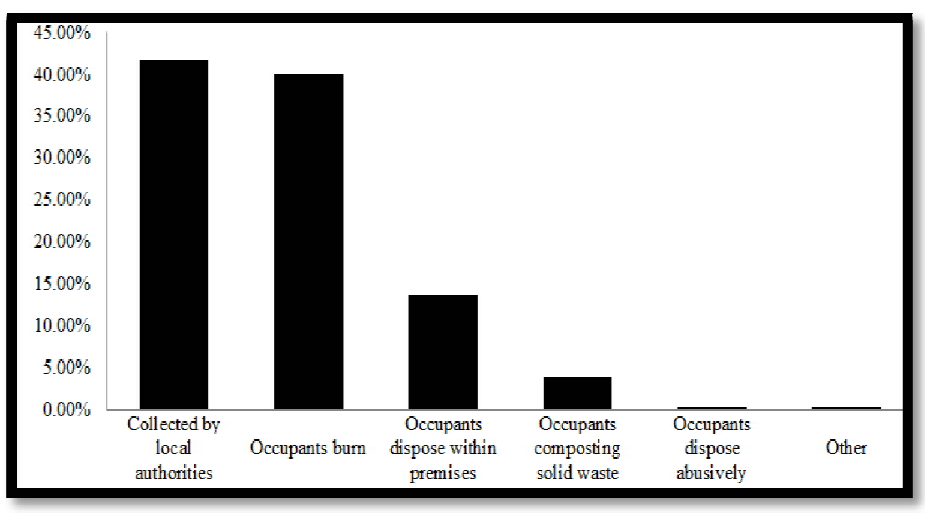

Figure 2: Mean Values of Waste Disposal in the Western Province of Sri Lanka Source: Western Province Provincial Council (2016)

As shown in Figure 2, 41.77 per cent of daily generated waste in WP is collected by local authorities (LAs), which end up in open dumping sites. Likewise, the main disposal methods used by residents who have no disposal facilities are burning and dumping within their premises. These practices are contradictory to the 3R principles. Therefore, a necessity has emerged in the context of WP to evaluate the applicability of SWM.

The disposal methods used in WP contribute to environmental pollution by emitting Green House Gases (GHG), such as carbon dioxide, nitrous oxide, perfluoro carbons, hydro-fluorocarbons, sulphur hexafluoride, methane and dioxins. The list is not exhaustive though.

Followed by Article 8 of the Rio Declaration on Environment and Development, the 3R principles have been accepted as the global standard for waste management practices Since 1992 (UNCED 1992). If these accepted SWM practices were followed reducing consumptions, reuse and recycle of waste by transport, transferring and processing to recover raw material and finally to dispose of the unrecoverable material safely could be a practicable in SWM (Dickey 2008). The 3R concept has been integrated to the National Policy of Solid Waste Management (NPoSWM) of Sri Lanka by the Section 5.1 of NPoSWM (Ministry of Environment and Natural Resources 2007). Simultaneously the National Strategy for Solid Waste Management (NSoSWM) in Sri Lanka was published in 2007. NPoSWM targeted to achieve 100 per cent of the goals fixed by NPoSWM; 6-10 years in long terms, i.e. from 2013 to 2017 (Wel \&Post 2007). Instead, in April 2017 in WP, 31 deaths were reported as a result of mismanaging the Meetotamulla waste dump site (Nafeel \& Bresnick 2017). Mass dumping is totally opposed to the terms fixed by NPoSWM and NSoSWM. According to reports on the Meetotamulla incident, the collapse was due to the failure of stability facilitated by heavy rain (Karunawardena et al. 2017). The incident reveals the real status of SWM in WP. A similar incident had already taken place in the Central Province and is likely to occur in other provinces of Sri Lanka.

SWM has been identified as a direct cause for the increase of global temperature by means of emissions from decaying waste (UNFCCC 2006). The emission of dioxins and methane and other GHG from decomposing waste contribute directly to Ozone depletion. 
As reported in 2012, in Sri Lanka, SWM is alleged to be responsible for 7,792 deaths due to respiratory diseases (WHO 2012).

Actual SWM in WP is also responsible for worsening the Dengue epidemic due to an increase of mosquitobreeding opportunities. It is pertinent to note that 42.3 per cent of the reported Dengue cases out of 59,760 cases for the first two quarters of 2017 were reported from WP (Epidemiology Unit, Ministry of Health 2017).

Leachate discharges from non-engineered waste dump sites have contributed to polluting the ground water in WP (Panabokke 2007). The whole of Sri Lanka is affected by unidentified kidney diseases, and there are multiple reasons for this. However, in the majority of cases, the kidney diseases had a direct relationship with the quality of drinking water.

SWM has been defined as 'the discipline associated with control of producing, storage, assortment, transference, treating and final disposal in a way that matches with the highest standard matching with health, conservation, economics, aesthetic, engineering and other environmental considerations' (Hwa 2007). Therefore, the effectiveness of SWM should have achieved through planning, administration, financial, engineering and legal functions in the process of solving problems associated with waste material.

An old Chinese proverb says that 'waste is a resource in the wrong place at the wrong time'(Napier 2006). Now, the available resources for human consumption are depleting rapidly. This fact of rapid depletion of resources increases the validity of the proverb today than the time it was coined.

There are important studies that are focused on explaining the component of SWM issues, narrowing it down to scientific standings. Some of the imminent issues covered in such studies are to understand the composition of leachate, the composition of waste, the composition of compost or the quality of polluted water in scientific terms. There are some studies which attempted to explain the SWM issue in economic terms (Weliwita 2014). However, no significant research has been done in the field of SWM form a sociological perspective. This research is an attempt to fill this research gap.

The primary aim of this research was to examine the effectiveness of SWM practices in the WP of Sri Lanka in light of the National Policy of SWM. Other aims are to understand relevant issues and strategies that should be taken to make SWM more effective. For the said purpose, the following hypotheses were formulated:

- $\mathrm{H}_{01}$ : The distribution of waste collection ratio across the types of LAs of the sample is normal

- $\mathrm{H}_{02}$ : The ratio of disposal of waste according to 3R principals, over total waste collected by LAs is $\geq 85 \%$

- $\mathrm{H}_{03}$ : There is no association between fund allocation and the effectiveness of SWM

- $\mathrm{H}_{04}$ : There is no association between the strength of legal framework and the effectiveness of SWM

- $\mathrm{H}_{05}$ : There is no association between real actions taken by stakeholders and the effectiveness of SWM

- $\mathrm{H}_{06}$ : There is no association between efficiency and effectiveness of real actions taken by stakeholders and the effectiveness of SWM

- $\mathrm{H}_{07}$ : There is no association between stakeholders' awareness and the effectiveness of SWM.

\section{Methodology}

Followed by the theoretical gap found, the primary research question asked was whether the current solid waste management practices in WP are effective or not in terms of targets fixed by NPoSWM. Some other research questions were: (a) Why current solid waste management practices in WP are not effective and (b) What are related issues pertinent to SWM?

The effectiveness of actual SWM practices adopted by the LAs in WP was the dependent variable.

\begin{tabular}{|l|c|c|}
\hline \multicolumn{1}{|c|}{ MC, UC and PS } & Daily Waste collection in MT & composting in MT \\
\hline Dehiwala-M. L. MC & 181.46 & 0.36 \\
\hline Moratuwa MC & 110.17 & 0.03 \\
\hline Sri Jayawardenepura Kotte MC & 78.19 & 0.02 \\
\hline Kaduwela MC & 107.61 & 0.04 \\
\hline Horana UC & 4.01 & 0.03 \\
\hline Maharagama UC & 76.47 & 0.00 \\
\hline Kesbewa UC & 57.01 & 0.13 \\
\hline Boralasgamuwa UC & 28.98 & 0.07 \\
\hline Homagama PS & 19.81 & 0.00 \\
\hline Seethawaka PS & 2.79 & 0.25 \\
\hline Horana PS & 2.38 & 0.30 \\
\hline Total Western Province & 668.87 & 1.23 \\
\hline
\end{tabular}

Table 1: The Daily Collection of Waste (In MT) and Correctly Disposal Rates (In MT)

Source: Western Province Provincial Council and Primary Data

Note: MC: Municipal Council; UC: Urban Council; PS: Pradeshiya Sabha

As demonstrated in Table 1, the only correct disposal method known to LAs in WP is composting. There are small commercial activities in Sri Lanka which are working in isolation to recover plastic, furnace oil, paper and metals. However, the recovery rates are negligible compared to total waste generations of respective categories. Notwithstanding 
that the majority of the LAs, as listed in Table 1, have composting facilities, the total composted mass is 0.15 per cent of the total waste collected. Indeed, at the Council meeting of the Moratuwa Municipality, an elected member of the Council compared, paradoxically, their municipal composting facility to a handicapped orphan (Fonseka 2016). This emphasizes the actual ineffectiveness of the composting process of the LAs. The situation can be observed as a common phenomenon in the whole of WP. The composting ratio of 0.15 per cent is a negligible figure to combine with waste collection ratio in order to compute a new dependent variable. Therefore, the daily waste collection ratio has been taken as the only component to set up the dependent variable. The factthat the Karadiyana dump site receives 680 metric tons (MT)of waste per day from the 11 LAs listed in Table 1, confirms that the entire collection, that is, 668.87 MT, is destined to be dumped (Maduranga 2016; Wicrama and others v. Moratuwa Municipal Council 2015). This revelation reinforces the selection of a mono parameter as the dependent variable, that is, waste collection ratio.

Five independent variables of the research had been conceptualized following the terms specified in NPoSWM. These are as follows: (a) the amount of fund allocated for SWM by LAs (ss 4.7), (b) the strength of legal framework (ss. 5.21), (c) real actions taken by stakeholders (ss. 3.2), (d) the effectiveness of actions taken by stakeholders in SWM (ss. 4.8) and (e) awareness of stakeholders in SWM (ss. 5.11).

To operationalize the fund allocation dimension, secondary data was used. Legal framework diminution was operationalized using three standard questions, each to represent the elements: legitimacy, neutrality and authority. To operationalize dimensions (c), (d) and (e), 12 questions were prepared to study the behaviour of four stakeholders, namely policy-makers, implementers (LAs), citizens and media.

The selection of WP as the research territory is justified, because 20.7 per cent of the total population of Sri Lanka is living in the province. The high population density in the province $\left(1,588\right.$ people $\left./ \mathrm{km}^{2}\right)$ has made SWM an immediate crisis in WP. The SWM emergency is less evident in other provinces where the population density mean value is 262 people/ $\mathrm{km}^{2}$ (Government Census 2016). Therefore, WP produces 60 per cent of the waste generated from Sri Lanka (Premachandra 2006).

The sampling technique adopted for the study is purposive sampling. In this method, all LAs that are dumping waste at the Karadiyana dump site were selected from the population of WP.

The sample selection was further justified, since it represents the homogeneous hierarchy of the LAs. As can be seen from Table 1, the sample includes four Municipal Councils (MC), four Urban Councils (UC) and three Pradeshiya Sabhas (PS). The selection of only three PS is justified by the fact that the geographical extent covered by a single Pradeshiya Sabha is greater than the sum of the extent of all the other eight LAs.

In the pilot research conducted to determine the sample size, 40 out of 45 citizens responded.

Therefore:

$p$, responsive rate $=89 \%$

$q$,non-responsive rate $=1-\mathrm{p}$

Thus, $q=11 \%$

The standard technique for sample size determination is as follows (Rose, Spinks \& Canhoto 2015):

$n=p \cdot q\left(\frac{Z_{\alpha} / 2}{e}\right)^{2}$

where $n=$ sample size

$e=$ error margin $(5 \%)$

$\alpha=$ confidence level

$Z_{\alpha / 2}=$ standardized normal distribution values

2 Then sample size adjusted by

$$
n^{\prime}=\frac{n}{1+(n / N)}
$$

Where $\mathrm{n}=$ adjusted sample size

$\mathrm{N}$ = population size

Calculating the sample size

$$
n=p \cdot q\left(\frac{Z_{\alpha} / 2}{e}\right)^{2}
$$

$p=89 \%$

$q=1-89 \%=11 \%$

$e=5 \%$ at $5 \%$ significant level

$$
n^{\prime}=\frac{n}{1+(n / N)}
$$


$=1.96$

$=150$

$$
\mathrm{n}^{\prime}=\frac{150}{1+(150 / 1,788,099)} \quad n=0.89 \times 0.11 x\left(\frac{1.96}{0.05}\right)^{2}
$$

Adjusted sample size, $n^{\prime}=149.987$

By using sampling techniques, the sample size adjusted to the population in the sample $(1,788,099)$ was determined as 150 .

A total of 187 individuals administered the survey where 15 questions were used in order to collect data. Seventeen (17) respondents from each LA were selected, out of which, 15 were randomly selected citizens attending public places and two were selected on behalf of each LA to represent the lowest hierarchy of SWM, waste collecting labourer and a supervisor.

Based on the responses received, a data matrix was prepared with the dependent variable as scale measure and independent variables as ordinal Likert scale measure. Then, four new independent variables were computed, taking mean values of element questions that were used to prove the principal dimensions under investigation.

As a prerequisite to computing a linear regression, assumptions of normality, linearity and equality of variances were tested. As shown in the Figure 3, standardized residual distributions were not normal across the sample. This signifies that regression analysis cannot beused to build a model.

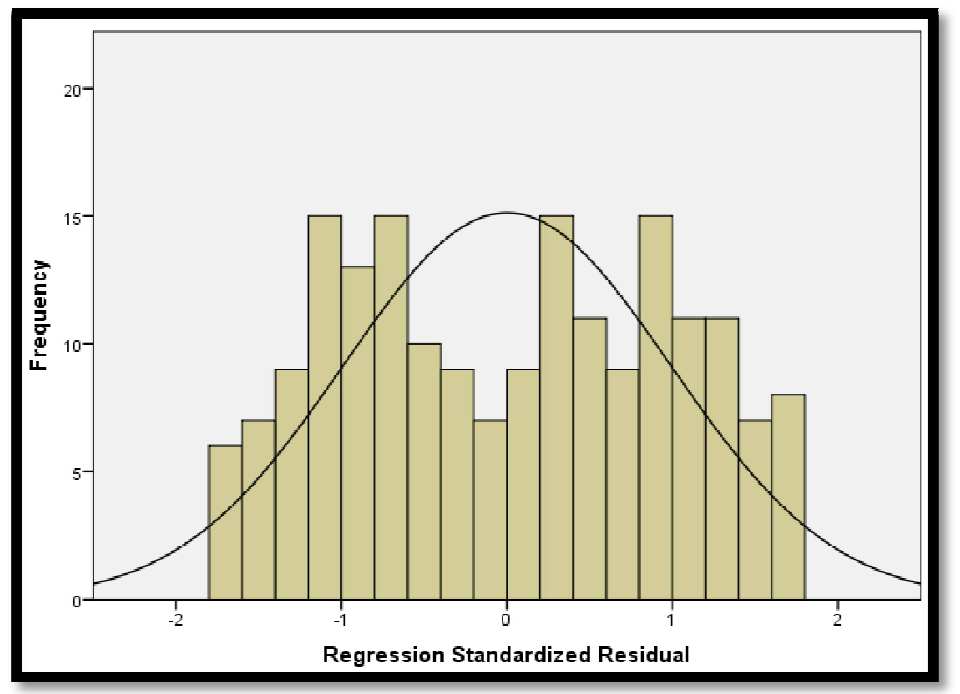

Figure 3: Standardized Residual Distributions

However, Spearman coefficient does not demand linear relationship as Pearson correlations coefficient. In determining the strength and direction of the association between two-scale and ordinal variables, the Spearman correlation coefficient procedure could be used, since it computes the pairwise associations for a set of variables and displays the results in a comprehensive matrix.

Pearson correlation coefficient works best when the variables are almost normally distributed and have no outliers. Since those conditions are not satisfied, Spearman correlation coefficient was considered for proving the correlation between the dependent and independent variables.

The formula for Spearman's rho is:

$$
r_{s}=\frac{6 \sum d^{2}}{n\left(n^{2}-1\right)}
$$

where $d$ is the difference of rank of order between the variables per person and $n$ is the number of persons in the research. In interpreting Spearman's rho, Cohen's conventions to construe effect size were used (Cohen 1988).

\section{Results}

One-sample nonparametric Kolmogorov Smirnov tests were applied to check the distribution of waste collection across the types of LAs, which produced the following results (Figure 4). 


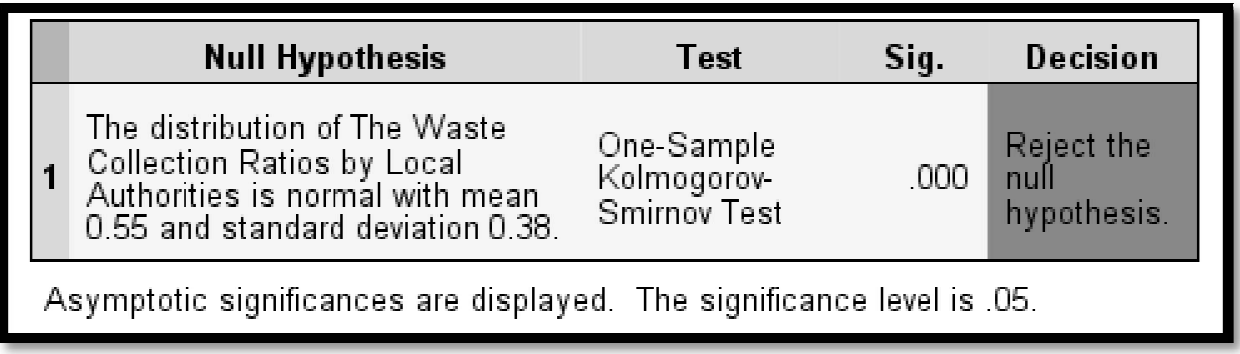

Figure 4: Waste Collection Ratios Through The Sample

The nonparametric one-sample binomial test was conducted in hypothesis testing, especially to check the null hypotheses, and it showed the results depicted in Figure 5.

\begin{tabular}{|c|c|c|c|c|}
\hline & Null Hypothesis & Test & Sig. & Decision \\
\hline 1 & $\begin{array}{l}\text { The categories defined by The } \\
\text { Waste Collection Ratios by Local } \\
\text { Authorities }<=0.85 \text { and }>0.85 \\
\text { occur with probabilities } 0.05 \text { and } \\
0.95 \text {. }\end{array}$ & $\begin{array}{l}\text { One-Sample } \\
\text { Binomial } \\
\text { Test }\end{array}$ & .000 & $\begin{array}{l}\text { Reject the } \\
\text { null } \\
\text { hypothesis. }\end{array}$ \\
\hline
\end{tabular}

Figure 5: Hypothesis Test Summary of Waste Collection Ratio

Table 2 shows results of analysis conducted using SPSS version 20, the statistical significance and Spearman correlation coefficients of the tested variables.

\begin{tabular}{|l|c|c|}
\hline & The Proportion of Waste Collection & Sig. (2-tailed) \\
\hline The proportion of Fund Allocation & $.525^{* *}$ & .000 \\
\hline Mean Vahe of Streng th of Leg al Framework & $.365^{* *}$ & .000 \\
\hline Mean Vahe of Efficiency of Actions by Stakeholders & $.252^{* *}$ & .000 \\
\hline Mean Vahue of Actions by Stakeholders & $.192^{* *}$ & .008 \\
\hline Mean Value of Awareness of Stakeholders & .137 & .061 \\
\hline
\end{tabular}

Table 2: Spearman Correlation Coefficient of Tested Variables

**Correlation Is Significant at the 0.01 Level (2-Tailed)

\section{Discussion}

Results confirm the alternative hypothesis by the rejection of the original null hypotheses- $\mathrm{H}_{01}$ and $\mathrm{H}_{02}$. The hypothesis test summary of waste collection ratio (Figure 2) confirms that it is not homogeneous across the categories of LAs. In the same way, the hypothesis test summary to determine the correctly disposed waste ratio (Figure 3) shows that it is less than 85 per cent. Therefore, both tests together confirm that the current solid waste management practices in the WP have not achieved the targets fixed by the NPoSWM.

The LAs in the sample discharge 680 MT of waste daily to their common dump site at Karadiyana. The figure nearly matches the daily waste collection by the LAs in the sample-668.87 MT. It gives an indication that approximately 98 per cent of the waste collected is disposed of at the dump site. These results confirm that LAs are not following the 3R principals promoted by NPoSWM.

According to Cohen correlations, figuresfrom 0.1-.029 are categorized as small, from $0.3-0.49$ as medium and from $0.50-1.00$ as strong relationships.

- Under the light of the results shown in Table 3 , there is significant evidence to reject the first null hypothesis, $\mathrm{H}_{01}$ $(p<0.05)$.

The Spearman correlation was 0.525 . This result concludes that there is a strong positive association between fund allocation for SWM and waste collection ratio by the LAs. A low level of fund allocation has been associated with a low level of waste collection. The result confirms that a high level of fund allocation for SWM over other socioeconomic activities would increase the effectiveness of SWM.

- There is significant evidence to reject the second null hypothesis, $\mathrm{H}_{02}(p<0.05)$. The Spearman correlation is 0.365 .

This concludes that there is a medium positive association between the strength of legal framework and waste collection ratio by the LAs. A low level of the strength of legal framework has been associated with low level of waste collection. The result confirms that when the strength of legal framework is weak, it is influencing the effectiveness of SWM practices. According to Transparency International Sri Lanka, the Corruption Perception Index (CPI) of Sri Lanka is 
95/176 (Transparency International 2017). To understand CPI, therank of 95/176 should be compared with that of a clean country like Sweden which ranks 1/176. The rank 1/176 has been attributed to Sri Lanka because where-law enforcing authorities such as Police Department, officers in environmental agencies and staff assisting the court are highly corruptible. Therefore, the result should be interpreted in the light of this index.

- There is significant evidence $(p<0.05)$ to reject the third and fourth null hypotheses $\left(\mathrm{H}_{03}\right.$ and $\left.\mathrm{H}_{04}\right)$. The Spearman correlation is 0.302 and 0.152 , respectively.

These positive correlations indicate that there are minor positive associations between real actions taken by stakeholders in SWM and the efficiency and the effectiveness of their actions to the dependent variable-the effectiveness of SWM. The result confirms that when stakeholders' real actions are efficient and effective, the effectiveness of SWM increases. This is a conclusion that largely in sync with common belief and findings of other researchers. When the stakeholders are dedicated to implementing the terms of NPoSWM, the effectiveness of SWM practices will increase.

- Finally, even though there is evidence to accept the fifth null hypothesis $\left(\mathrm{H}_{05}\right)$ at 95 per cent confident level $(p=$ 0.61 ), it still could be rejected at 90 per cent confidence level.

In contrast with hard sciences, the variables measured are opinions of people, so it is quite reasonable to change the degree of confidence level marginally to 90 per cent in order to reject the null hypothesis. The Spearman correlation is 0.137. This concludes that there is a weak positive association between awareness of stakeholders and effectiveness of SWM.

The result confirms that when the awareness of stakeholders increases, the effectiveness of SWM also increases. As the previous dimension tested, the present conclusion goes hand in hand with the common belief and findings of researchers who conducted research in the field of SWM.

The research could not be used to produce a model that can be used to increase the effectiveness of SWM. However, Figure 6 depicts dimensions and their strengths, which will help in making SWM more effective in the WP of Sri Lanka.

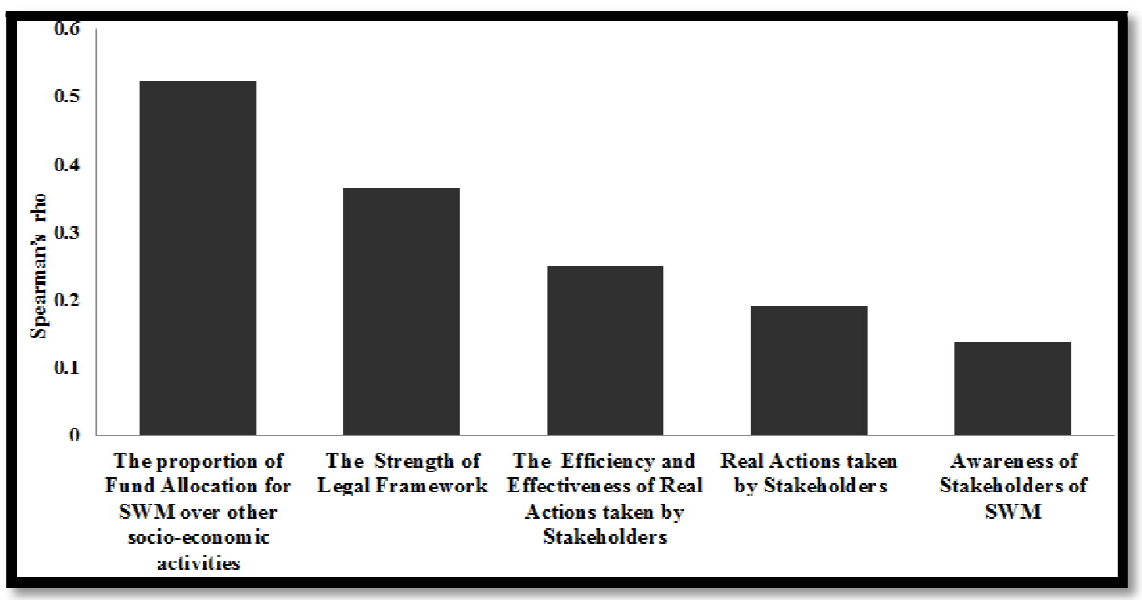

Figure 6: Dimensions of Effectiveness of SWM Practices of WP Of SL

The proportion of fund allocation is the highest influencing factor in terms of effectiveness of SWM in WP. This is not a surprising revelation because, without the infrastructure for SWM, the desired level of effectiveness cannot be obtained. The second important factor has been the strength of the legal framework. Without having a strong legal framework, it is not possible to achieve socio-cultural changes to utilize such constructed infrastructures. The next is efficiency and effectiveness of the real actions taken by stakeholders. Though $r$ values of the real actions taken by stakeholders and efficiency and effectiveness of such actions are statistically weak, they are still relevant. The interpretation is that without stakeholders' effective actions, the desired effectiveness will an endeavour hard to achieve. Results explain that awareness of stakeholders in SWM would have increased only after completing all the above steps, not vice versa.

Such a practice has emerged due to the erroneous interpretation of education psychology. This erroneous interpretation leads the way to diminish the efficacy such environmental teaching programs due to two major factors. First, when there is a contradiction between what schoolchildren are thought at schools and what they are observing about actual SWM practices or actual social behaviour of SWM that they are surrounded with, they are psychologically refusing what they were thought by forced teaching programmes. This is a social theory metaphorically described as 'the theory of broken window.' It explains that when a broken window of a city is repaired immediately, it becomes the social standard of that city, whereas, if not repaired, then the degradation of the entire city represented by the broken windows would spread as a social phenomenon. The second factor is that without infrastructure schoolchildren have no means to practice what they are taught. These findings are justified by the current ineffective state of SWM even after the implementation of awareness programmes that had been implemented in schools in Sri Lanka for the past two decades. The irony of the SWM in Sri Lanka is while awareness programmes are continuously being implemented in schools and policy-makers are also regularly visiting developed foreign countries in order to increase their own awareness. However, no observable improvement in the SWM practices were reported by the responding participants of this research notwithstanding those awareness programs widely implemented. The same result was confirmed by the analysis of secondary data. 
Results further confirm that LAs are not following the guidelines set by NPoSWM.

As a concluding thought, to achieve an effective SWM, the paper recommends an increase in the allocation of fund for building infrastructure for SWM and the strengthening of law enforcement to ensure the functioning of such infrastructure through effective real actions by stakeholders. It is highly recommended that we need to think globally about SWM and act locally to realize the targets fixed by UNCED (UNCED 1992).

The results could be generalized to all other provinces of Sri Lanka. It can further be extended to many of the developing countries of the world that are using dumping as the principal disposal method with higher corruption indices, such as India, Bangladesh and Pakistan.

\section{Limitations of the Research}

The research methodology adopted in this research was strictly quantitative. The investigation was carried out with predetermined conceptual framework operationalized by asking a single question for each element tested. A presumption was made that each such single question represents the entire element that constitutes dimensions. However, a single question and the five-scale response may not reasonably be sufficient to represent a vast social phenomenon under investigation. Therefore, it is recommended that future studies adopt a deductive approach to conduct interviews yielding opinions from people (Glaser \& Strauss2012). Such data triangulation will guarantee the validity and reliability of future researches.

\section{References}

i. Cohen, J 1988, Statistical power analysis for the behavioural sciences (2nd ed.), Lawrence Erlbaum Associates Publishers, Hillsdale.

ii. Rose, S Spinks, N \& Canhoto, A 2015, Management research, Taylor and Francis, Abingdon.

iii. Dickey, D2008, A 4R's guide: For the first nations communities of Quebec and Labrador, First Nations of Quebec and Labrador Sustainable Development Institute (FNQLSDI). Viewed 7 August 2017

http://fnqlsdi.ca/wp-content/uploads/2013/05/4rsguide_eng.pdf

iv. EC (European Commission), 2016, Waste policy review: Environment, Ec.europa.eu, Viewed 7 August 2017 http://ec.europa.eu/environment/waste/target_review.htm

v. Epidemiology Unit, Ministry of Health,2017,Distribution of notification (H399) Dengue cases by month, Disease Surveillance-Trends, Colombo, Viewed 8 August 2017,

http://www.epid.gov.lk/web/index.php?option=com_casesanddeaths \&Itemid=448\&lang=en\#

vi. Fonseka, R 2016, Moratuwa municipal council monthly meeting. Lankadeepa, 31 June, p.6.

vii. Glaser, B G\& Strauss, A L 2012, The discovery of grounded theory: Strategies for qualitative research, Aldine Transaction, New Brunswick.

viii. Gordon, R 2015, The history of the three R's. Recycle Nation, Viewed 7 August 2017, fromhttps://recyclenation.com/2015/05/history-of-three-r-s/

ix. Government Census, 2016,Statistical data sheets 2016,In District statistical handbook 2016, Department of Census and Statistics, Battaramulla, Viewed 9 August 2017 http://www.statistics.gov.lk/DistrictStatHBook.asp

$\mathrm{x}$. Hwa, T2007 'Overview of solid-waste management in Asian countries', Solid waste management: Issues and challenges in Asia, pp.3-7, Viewed 8 August 2017 http://www.apo-tokyo.org/00e-books/IS-22_SolidWasteMgt/IS22_SolidWasteMgt.pdf

xi. Karunawardena, W,Bandara, R, Bandara, K, Sugathapala, K, Jayasinghe, P, Indrathilaka, L \& Galhena, G2017, Geotechnical assessment on the failure at Meethotamulla waste fill, National Building Research Organisation, Colombo, Viewed 8 August 2017http://www.nbro.gov.lk/images/2016_pdf/Final-Report-of-Meethotamulla-toMegapolis-PDF.pdf

xii. Maduranga, A2016, Come to see Karadiayana dumping site, ADA, January 5, p.1.

xiii. Ministry of Environment and Natural Resources, 2007, National Policy of Solid Waste Management, Ministry of Environment and Natural Resources, Battaramulla, $\mathrm{P} 4$.

xiv. Nafeel, N\& Bresnick, S 2017 Meethotamulla death toll rises to 31. Daily News, April 19 p.1. Viewed 8 August 2017 http://dailynews.lk/2017/04/19/local/113546/meethotamulla-death-toll-rises-31

xv. Napier, T2006, Alternatives to demolition: Opportunities to deconstruct, reuse \& recycle building materials. US Army Corps of Engineers, Champaign, Viewed 28 August 2017,

http://www4.uwm.edu/cbu/Presentations/UWM\%20Sustainability\%206\%20Mar\%2006.pdf

xvi. Panabokke, C2007, Groundwater conditions in Sri Lanka, National Science Foundation of Sri Lanka, Colombo, p 39.

xvii. Premachandra, H.2006Household waste composting \&MSW recycling in Sri Lanka, Presentation at Asia 3R Conference, Tokyo, 29 October-01 November 2006.

xviii. Scottish Government, 2014, 'Waste', Scotland's Environment Web, Viewed 7 August 2017, http://www.environment.scotland.gov.uk/media/18031/waste_fig1.jpg

xix. Tainter, J2009, The collapse of complex societies, 2nd ed., Cambridge, University Press, p 129.

xx. Transparency International, 2017, The corruption perceptions index 2016, Viewed 30 August 2017, https://www.transparency.org/country/LKA

xxi. UNCED, 1992, Report of the United Nations Conference on Environment and Development (A/CONF.151/26 [Vol. I]), Un.org. Viewed 26 May 2017,http://www.un.org/documents/ga/conf151/aconf15126-1annex1.htm

xxii. UNFCCC, 2006, Amendment to Annex $B$ of the Kyoto Protocol, Unfccc.int, Viewed 7 August 2017,http://unfccc.int/kyoto_protocol/amendment_to_annex_b/items/4082.php 
xxiii. Wel, A \& Post, V2007, 'CORDAID tsunami reconstruction 4 project report,, 3R Waste Foundation, Hague, Viewed, 8 August 2017, http://www.cepa.lk/content_images/publications/documents/173-S-WASTE-

SWM\%20in\%20SL.pdf

xxiv. Weliwita, I 2014, Designing an economic instrument for sustainable solid waste management in the household sector, PhD Thesis, University of Portsmouth.

xxv. Western Province Provincial Council (WPPC), No. of households by principal method of solid waste disposal and local authority, Viewed, 8 August 2016,http://alumnifgs.org/WPPC_backuped_SWM_Report.png

xxvi. WHO, 2012, Ambient air pollution burden of disease: Databy country, Public health and environment, Global Health Observatory data repository, Viewed 8 August 2017, http://apps.who.int/gho/data/node.main.152?lang=en

xxvii. Wicrama and others v. Moratuwa Municipal Council, 'Public nuisances case no. 6304', Kesbewa Magistrate Court, 2016. 